\title{
石墨烯的功能与应用一一规模制备和能源相关应用
}

\author{
王斌 1 , 智林杰 ${ }^{1,2}$ \\ 1 国家纳米科学中心, 纳米科学卓越创新中心, 纳米系统与多级次制造重点实验室, 北京 100190 \\ 2 中国科学院大学, 北京 100049
}

\section{Graphene: Functions and Applications-Batch Production and Energy-Related Applications}

\author{
Bin Wang ${ }^{1}$, Linjie Zhi ${ }^{1,2}$ \\ ${ }^{1}$ CAS Key Laboratory of Nanosystem and Hierarchical Fabrication, CAS Center for Excellence in Nanoscience, National Center for \\ Nanoscience and Technology, Beijing 100190, China. \\ ${ }^{2}$ University of Chinese Academy of Sciences, Beijing 100049, China.
}

Emails: wangb@nanoctr.cn (B.W.); zhilj@nanoctr.cn (L.Z.).

Published online: April 7, 2021.

2004年曼彻斯特大学报道了首个具有明确结 构的石墨烯材料 ${ }^{1}$, 其优异的物理化学性质引起了 科学界和工业界的持续关注。经过十几年的探索, 石墨烯的规模化制备和应用已取得了长足的进 步, 尤其是在能源存储和转化等领域展现出了广 阔的应用前景。本专刊收集了国内部分科学家在 相关领域的研究成果, 分成两期在 2022 年第 1 期和 第2期印刷出版。上一期围绕高质量石墨烯的生 长、性质调控和新功能器件的开发展开了讨论, 本 期则聚焦在石墨烯的规模化制备和在能源相关领 域的实际应用方面。

刘忠范团队在高质量石墨烯的化学气相沉积 生长(CVD)方面有长期的积累, 并实现了石墨烯晶 圆的批量制备。基于此, 从使用规范和应用场景出 发, 他们 ${ }^{2}$ 介绍了石墨烯晶圆的标号化制备需求, 提出按照石墨烯的品质进行等级分类, 形成面向 应用的技术标准, 并重点论述了CVD规模化制备 技术, 分析了未来可能的发展方向, 对石墨烯切实 走进人们的生活提出了期望。除二维形态外, 石墨 烯也可以形成一维纤维材料, 而根据结构的不同 可以将石墨烯纤维分为两大类: 一类是通过片层 的紧密有序堆积形成一维宏观材料, 另一类是利 用 CVD的方法将石墨烯沉积在其它的纤维材料 上, 形成复合功能材料。刘忠范团队对这两种石墨
烯纤维的发展现状分别进行了总结。首先介绍了 通过湿法纺丝、限域水热等组装方法制备石墨烯 纤维的过程 ${ }^{3}$, 详细阐述了其性能及提升策略, 并 对此类纤维的应用方向进行了归纳和展望。其次, 他们介绍了模板法CVD生长石墨烯复合纤维的技 术 ${ }^{4}$, 如在石英纤维、光纤等材料上进行沉积的过 程控制和相应的力、电、光学性质, 及其在智能传 感、光学器件、柔性电极等领域的应用。

石墨烯规模化制备技术的日趋成熟推动了其 在多个应用领域研究的快速发展, 如催化、储能、 散热、光电转换、功能涂料等。其中, 能源问题是 人类生存的根本问题。在 2020 年 9 月第 75 届联合国 大会上, 习近平总书记向全世界做出 “力争于 2030年前二氧化碳排放达到峰值, 努力争取 2060 年前实现碳中和” 的承诺。发展绿色储能技术和 二氧化碳的高效还原技术是实现低碳经济的两个 重要手段。

在储能电池方面, 宋怀河等 5 从石墨烯的实用 化角度出发, 研究了石墨烯包覆天然球形石墨用 作锂离子电池负极材料时, 乙炔黑导电剂的添加 对其电化学性能的影响。在此过程中, 石墨烯不仅 作为活性物质, 也可作为导电剂来使用, 而乙炔黑 则发挥桥连作用, 与石墨烯协同形成更加高效的 导电网络, 提高了电池的容量。何海勇等6则采用 
还原氧化石墨烯对剥离石墨进行包覆, 剥离石墨 的大层间距的特点有利于钾离子的快速脱嵌过 程, 同时也抑制了剥离石墨的堆叠, 增强了石墨基 负极在钾离子电池中的稳定性。吴明铂等 ${ }^{7}$ 综述了 近年来表面化学修饰的石墨烯、石墨烯基复合材 料以及柔性材料等在锂硫电池正极中的研究现 状, 展望了石墨烯作为硫载体在锂硫电池正极中 的发展前景。范壮军等 8 从石墨烯基的超级电容器 器件出发, 系统总结了石墨烯薄膜的简易制备方 法, 综述了通过结构调控和表面修饰等方法来优 化石墨烯薄膜电化学性能的策略, 并对石墨烯薄 膜应用所面临的挑战和未来的发展进行了总结和 展望。

利用电催化技术将二氧化碳转化为小分子燃 料或高附加值化学品是构建人工碳循环的绿色能 源技术之一。邱介山等 9 评述了石墨烯基材料在该 领域的研究进展, 详述了石墨烯基电催化剂的构 筑方法, 探讨并梳理了石墨烯的点/线缺陷、表面 官能团、掺杂原子构型、金属单原子种类、材料表 界面性质等与还原反应的本征构效关系。智林杰 等 ${ }^{10}$ 通过热解含镍金属的有机框架材料和二腈二 胺制备了高载量镍单原子 $(7.77 \%, w)$ 负载的超薄 氮掺杂碳纳米片, 其在较宽的电压窗口内 $(-0.77$ 到 $-1.07 \mathrm{~V} v s$. RHE)产生一氧化碳的选择性都高于 $90 \%$, 且具有优良的稳定性。该结果表明, 采用有 机框架材料为前驱体制备二维碳纳米片可以实现 高效负载金属原子的功能性催化材料, 对高选择 性的二氧化碳还原催化剂的结构设计和制备有指 导意义。

尽管石墨烯的高质量制备和结构、功能控制 还存在许多困难与问题, 但是石墨烯在许多领域 的实际应用却也在快速发展。特别是利用石墨烯 中存在的结构缺陷导致的特殊功能, 使其在催化、 电化学转化、光电转化、电热转化等领域具有良好 的应用前景。石墨烯通过化学改性、结构优化、多 组分复合等手段更是可以有针对性地优化其在实 际使用中的性能, 从而在二次电池、超级电容器、 太阳能利用、导热散热、防护涂层、过滤净化、生 物传感等领域发挥重要作用。这些应用研究在学
术界和产业界正在受到越来越多的重视, 其中的 有些研究成果正在逐渐实现商业化应用, 相信在 不远的将来会逐步走进人们的生活。

\section{References}

(1) Novoselov, K. S.; Geim, A. K.; Morozov, S. V.; Jiang, D.; Zhang, Y.; Dubonos, S. V.; Grigorieva, I. V.; Firsov, A. A. Science 2004, 306, 666. doi: $10.1126 /$ science. 1102896

(2) Jiang, B.; Sun, J. Y.; Liu, Z. F. Acta Phys. -Chim. Sin. 2022, 38 (2), 2007068. [姜蓓, 孙靖宇, 刘忠范. 物理化学学报, 2022, 38 (2), 2007068.] doi: 10.3866/PKU.WHXB202007068

(3) Jian, M. Q.; Zhang, Y. Y.; Liu, Z. F. Acta Phys. -Chim. Sin. 2022, 38 (2), 2007093. [寒木强, 张芗芗, 刘忠范. 物理化学学报, 2022, 38 (2), 2007093.] doi: 10.3866/PKU.WHXB202007093

(4) Cheng, Y.; Wang, K.; Qi, Y.; Liu, Z. F. Acta Phys. -Chim. Sin. 2022, 38 (2), 2006046. [程熠, 王坤, 元月, 刘忠范. 物理化学学报, 2022, 38 (2), 2006046.] doi: 10.3866/PKU.WHXB202006046

(5) Liu, X. W.; Niu, Y.; Cao, R. X.; Chen, X. H.; Shang, H. Y.; Song, H. H. Acta Phys. -Chim. Sin. 2022, 38 (2), 2012062. [刘学伟, 牛芗, 曹 瑞雄, 陈晓红, 商红岩, 宋怀河. 物理化学学报, 2022, 38 (2), 2012062.] doi: 10.3866/PKU.WHXB202012062

(6) Wang, J.; Yin, B.; Gao, T.; Wang, X. Y.; Li, W.; Hong, X. X.; Wang, Z. Q.; He, H. Y. Acta Phys. -Chim. Sin. 2022, 38 (2), 2012088. [王键, 尹波, 高天, 王星懿, 李望, 洪兴星, 汪竹青, 何海勇. 物理化学 学报, 2022, 38 (2), 2012088.] doi: 10.3866/PKU.WHXB202012088

(7) Zhang, M. D.; Chen, B.; Wu, M. B. Acta Phys. -Chim. Sin. 2022, 38 (2), 2101001. [张梦迪, 陈蓓, 吴明铂. 物理化学学报, 2022, 38 (2), 2101001.] doi: 10.3866/PKU.WHXB202101001

(8) Jiang, M. H.; Sheng, L. Z.; Wang, C.; Jiang, L. L.; Fan, Z. J. Acta Phys. -Chim. Sin. 2022, 38 (2), 2012085. [姜美慧, 盛利志, 王超, 江丽丽, 范壮军. 物理化学学报, 2022, 38 (2), 2012085.] doi: 10.3866/PKU.WHXB202012085

(9) Du, Y. D.; Meng, X. D.; Wang, Z.; Zhao, X.; Qiu, J. S. Acta Phys. -Chim. Sin. 2022, 38 (2), 2101009. [杜亚东, 孟祥桐, 汪珍, 赵金金, 邱介山. 物理化学学报, 2022, 38 (2), 2101009.] doi: 10.3866/PKU.WHXB202101009

(10) Huang, X. X.; Ma, Y. J.; Zhi, L. J. Acta Phys. -Chim. Sin. 2022, 38 (2), 2011050. [黄小雄, 马英杰, 智林杰. 物理化学学报, 2022, 38 (2), 2011050.] doi: 10.3866/PKU.WHXB202011050 